\title{
Absolute Diffusion Process: Sensitivity Measures
}

\author{
Manuela Larguinho, José Carlos Dias, and Carlos A. Braumann
}

\begin{abstract}
The constant elasticity of variance (CEV) model of Cox (Notes on Option Pricing I: Constant Elasticity of Variance Diffusions. Working paper, Stanford University (1975)) captures the implied volatility smile that is similar to the volatility curves observed in practice. This diffusion process has been used for pricing several financial option contracts.

In this paper we present the analytical expressions of sensitivity measures for the absolute diffusion process, commonly known as Greeks, and we analyze numerically the behavior of the measures for European options under the CEV model.
\end{abstract}

\section{Introduction}

Under the risk-neutral probability measure $\mathrm{Q}$, the constant elasticity of variance (CEV) process of [4] assumes that the asset price $\left\{S_{t} ; t \geq 0\right\}$ is described by the following stochastic differential equation:

\footnotetext{
M. Larguinho ( $₫)$

Centro de Investigação em Matemática e Aplicações, Universidade de Évora and Department of Mathematics, ISCAC, Quinta Agrícola, Bencata, 3040-316 Coimbra, Portugal e-mail: mlarguinho@iscac.pt

J.C. Dias

BRU-UNIDE and ISCTE-IUL Business School, Complexo INDEG/ISCTE, Av. Prof. Aníbal Bettencourt, 1600-189 Lisboa, Portugal e-mail: jose.carlos.dias@iscte.pt

C.A. Braumann

Centro de Investigação em Matemática e Aplicações, Universidade de Évora, Rua Romão Ramalho 59, 7000-671 Évora, Portugal

e-mail: braumann@uevora.pt
}

J. Lita da Silva et al. (eds.), Advances in Regression, Survival Analysis, Extreme Values, Markov Processes and Other Statistical Applications, Studies in Theoretical and Applied Statistics, DOI 10.1007/978-3-642-34904-1_26,

(c) Springer-Verlag Berlin Heidelberg 2013 